\title{
Acute retrograde aortic dissection: "To be [treated] or not to be, that is the question"
}

\author{
Patrick T. Roughneen, MD, ${ }^{\mathrm{a}}$ Grant T. Fankhauser, MD, ${ }^{\mathrm{b}}$ and Abe DeAnda, Jr, $\mathrm{MD}^{\mathrm{a}}$
}

\author{
From the Divisions of a Cardiothoracic Surgery, and ${ }^{b}$ Vascular Surgery, Department of Surgery, University of \\ Texas Medical Branch-Galveston, Galveston, Tex. \\ Disclosures: Authors have nothing to disclose with regard to commercial support. \\ Received for publication Sept 29, 2016; accepted for publication Sept 30, 2016. \\ Address for reprints: Abe DeAnda, Jr, MD, Division of Cardiothoracic Surgery, UTMB-Galveston, 301 Univer- \\ sity Blvd, Galveston, TX 77555-0528 (E-mail: abdeanda@UTMB.edu). \\ J Thorac Cardiovasc Surg 2017;153:66-7 \\ $0022-5223 / \$ 36.00$ \\ Copyright (c) 2016 by The American Association for Thoracic Surgery \\ http://dx.doi.org/10.1016/j.jtcvs.2016.09.077
}

The Stanford classification of aortic dissection simplified the clinical approach to the management of this disease, with type A aortic dissection (TAAD) (Figure 1) requiring surgical intervention and type B primarily medical management $^{1}$ and chronicity defined as presentation later than 2 weeks from the onset of symptoms. Inherent in this schema was recognition of the presence (type A) or absence (type B) of a false lumen in the ascending aorta, independent of the origin of the primary intimal tear. The earlier DeBakey classification ${ }^{2}$ did specify both the origin and propagation of the false lumen, but, as noted by Lansman and colleagues, ${ }^{3}$ linked the "given tear with a given direction and extent of propagation," thus effectively excluding the situation of the de novo retrograde type A dissection (RTAD). Not easily addressed in either classification was the dissection that began in the arch and propagated distally $\left(23 \%\right.$ of cases $\left.^{3}\right)$ or the type $\mathrm{B}$ dissection with retrograde extension limited to the arch $(16.5 \%$ of cases $^{4}$ ). The guiding principle is that when the dissection involves the ascending aorta, whether as the initiating site or secondary to a RTAD, open surgical repair is the accepted approach.

In this issue of the Journal, Zhang and colleagues 5 describe a 2-stage endovascular approach that involves a novel approach to inducing thrombosis of the false lumen in the ascending aorta and arch. Their approach, which advocates delayed pretreatment of retrograde extension of a distal dissection into the aortic arch and ascending aorta, is novel, uncharted, and thought provoking. In their series of 9 patients, they waited 14 or more days to pretreat the retrograde acute dissection with a combination of endovascularly deployed coils and Onyx glue (Medtronic, Minneapolis, Minn) embolization. This resulted in the occlusion of the proximal dissection, thereby establishing a landing zone for eventual endovascular treatment of the distal tear. In follow-up of 1 year, all patients survived and sustained no complication or repeat dissection.

Their data, and the known natural history of untreated TAAD within the initial 14-day nontreatment period to

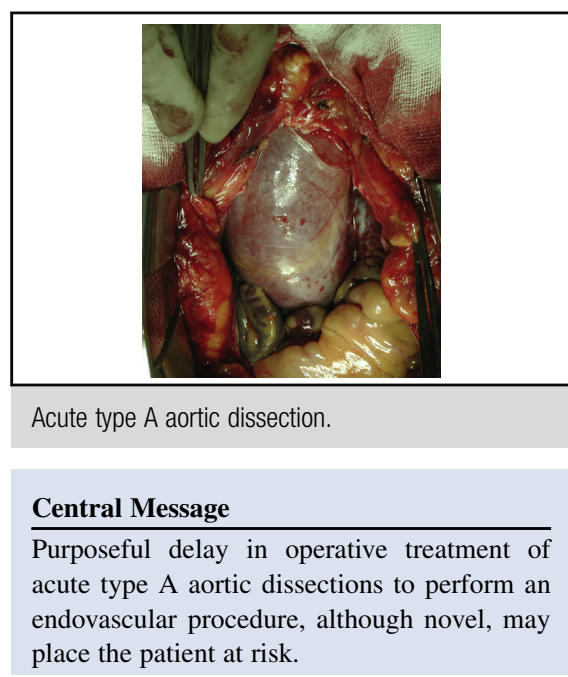

See Article page 57.

which all 9 patients were subjected, raises significant concerns about the wisdom of such an approach to an acute dissection involving the ascending aorta, albeit retrograde in nature. First, Zhang and colleagues ${ }^{5}$ cite data of systolic and diastolic pressure measurements in the true and false lumens (both before and after treatment) in the aortic arch that clearly indicate that the false lumen of the transverse aorta was still subjected to a mean pressure in excess of $75 \mathrm{~mm}$ $\mathrm{Hg}$ during the first 14 days of acute dissection, potentially furthering progressive retrograde dissection in both the aortic arch and ascending aorta, a point they freely admit in discussion of their results. Second, the history of acute aortic dissection has taught us two facts: untreated acute dissection, whether antegrade or retrograde, in the ascending aorta can ultimately involve the coronary anatomy and the aortic valve and can lead to frank rupture into the pericardium. The mortality from acute TAAD is $1 \%$ each hour for the first 48 hours of initiation of the dissection; the mortality from RTAD is unknown but presumably not insignificant. During the 14-day period before the first-stage surgical procedure, the 9 patients reported on by Zhang and colleagues ${ }^{5}$ were subjected to such risks while the attempt was made to convert the aortic dissection into its chronic phase. This remains a highly lethal window to achieve an endovascular result.

The drive behind such an approach is that perioperative mortality for emergency repair of type A dissection is $10 \%$ to $35 \%$ and that the hemodynamics, characteristics, 


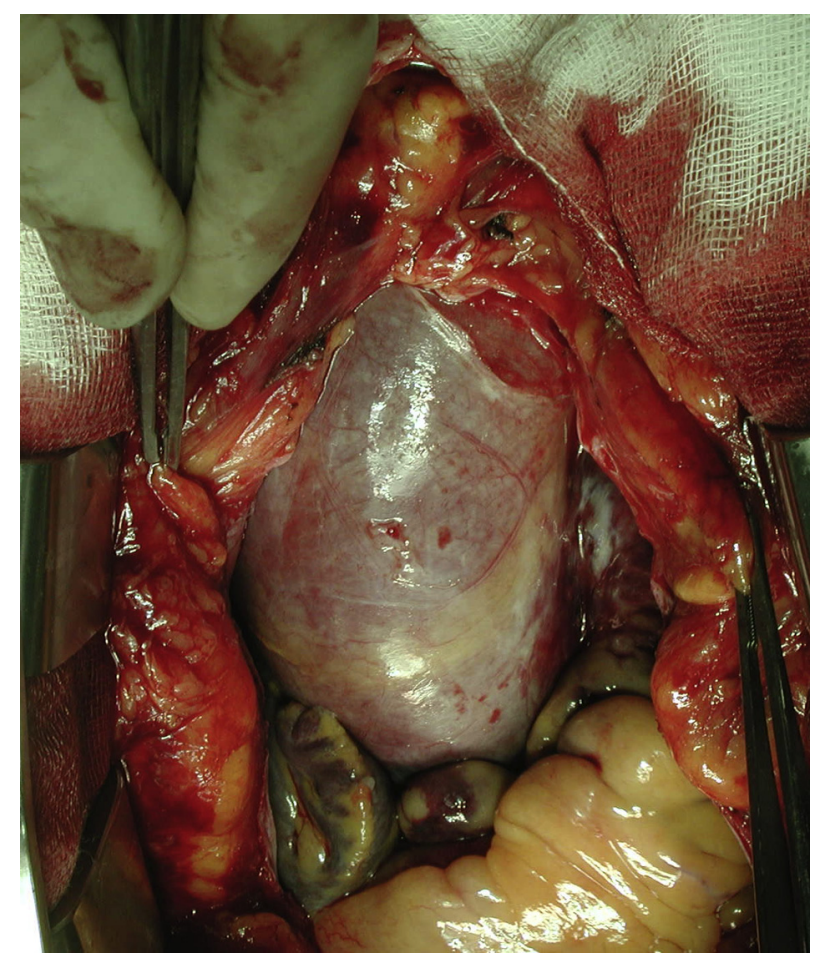

FIGURE 1. Acute type A aortic dissection.

process of dissection and prognosis are different between RTAD and TAAD. Kim and associates ${ }^{6}$ and Kaji and colleagues $^{7}$ evaluated acute surgical treatment of RTAD and TAAD and did not allow a 14-day window before the initiation of treatment in either group. Simply put, patients with RTADs do better than patients with TAADs when they are both treated with emergency surgery, but that cannot be extrapolated to imply that RTAD with a nonthrombosed false lumen is not a lethal condition if not treated with emergency surgery.

The pretreatment that Zhang and colleagues ${ }^{5}$ propose is not without risk, although no complications were reported in their small series. Embolization coils and Onyx glue are subject to migration and unintended distal embolization. ${ }^{8,9}$ In the aortic arch, even with an intimal tear distal to the left subclavian artery, there is a theoretic risk of embolization to the great vessels. This risk must be considered when deciding between a conventional repair and the method of Zhang and colleagues.

In this article, Zhang and colleagues ${ }^{5}$ advocate a 14-day risk period to allow them ultimately to achieve catheterbased induction of thrombosis in the false lumen in the retrograde dissection and convert to a chronic state for endovascular treatment of a descending aortic dissection. For us to ignore the natural untreated history of acute RTAD in the ascending aorta in a hastened adoption of such treatment options may only serve to reenlighten us to the consequences.

\section{References}

1. Daily PO, Trueblood HW, Stinson EB, Wuerflein RD, Shumway NE. Management of acute aortic dissections. Ann Thorac Surg. 1970;10:237-47.

2. DeBakey ME, Henly WS, Cooley DA, Crawford ES, Morris GC. Surgical treatment of dissecting aneurysms of the aorta: analysis of seventy-two cases. Circulation. 1961;24:290-303.

3. Lansman SL, McCullough JN, Nguyen KH, Spielvogel D, Klein JJ, Galla JD, et al Subtypes of acute aortic dissection. Ann Thorac Surg. 1999;67:1975-8; discussion 1979-80.

4. Nauta FJ, Tolenaar JL, Patel HJ, Appoo JJ, Tsai TT, Desai ND, et al; all International Registry of Acute Aortic Dissection (IRAD) Investigators. Impact of retrograde arch extension in acute Type B aortic dissection on management and outcomes. Ann Thorac Surg. July 14, 2016 [Epub ahead of print].

5. Zhang R, Zhou J, Feng J, Zhao Z, Liu J, Li Z, et al. Inducing false lumen thrombosis for retrograde type A aortic dissection. J Thorac Cardiovasc Surg. 2017;153: $57-65$.

6. Kim JB, Choo SJ, Kim WK, Kim HJ, Jung SH, Chung CH, et al. Outcomes of acute retrograde type A aortic dissection with an entry tear in descending aorta. Circulation. 2014;130(11 Suppl 1):S39-44.

7. Kaji S, Akasaka T, Katayama M, Yamamuro A, Yamabe K, Tamita K, et al Prognosis of retrograde dissection from the descending to the ascending aorta. Circulation. 2003;108(Supp1 1):II300-6.

8. Lind BB, Briggs CS, Golan J, Gupta N. Embolization of Onyx causing acute limb ischemia. Ann Vasc Surg. August 20, 2016 [Epub ahead of print].

9. Lee K, Park HS, Lee T. Rescue therapy of inadvertent coil migration for endovascular treatment of type II endoleak. Vasc Specialist Int. 2016;32:22-5. 